\title{
Observation of Online Foreign Language Teaching Model Based on Massive Open Online Course and Small Private Online Course During COVID-19 School Closure
}

\section{A Case Study Based on the Elective Course of Spanish in Chinese Universities}

\author{
Li Yan ${ }^{1, *}$ \\ ${ }^{1}$ School of Translation Studies, Jinan University, Zhuhai, Guangdong, China \\ "Corresponding author. Email: Yanli@jnu.edu.cn
}

\begin{abstract}
During the COVID-19 epidemic, China, like other countries in the world, has adopted quarantine measures in schools and universities. Teachers were confronted with the need to adapt to online teaching. The author has observed and reflects on the online foreign language teaching model of Jinan University of China from three aspects: basic concepts and practices of online learning, the forms and characteristics of Spanish online learning during the epidemic, and the challenges countermeasures of online foreign language teaching. The research shows that online teaching is still in its exploratory and experimental stage, with a massive space for improvement in the network environment, classroom interaction, teacher training, teaching resources, etc. Besides, to adopt a future-oriented vision, it is necessary to consider the advantages, disadvantages, opportunities, and threats that the emerging information technologies like 5G, virtual reality technology, and holographic imaging technology will bring to future online foreign language education.
\end{abstract}

Keywords: COVID-19, online foreign language teaching model, Chinese universities

\section{INTRODUCTION}

As the first nation in the world to have the COVID19 outbreak, China, like other countries globally, has adopted large-scale quarantine measures, which has obligated all schools and universities' teaching work to be transferred from face to face classroom teaching to online teaching in early March. Although schools in some areas began to resume classroom teaching in midMay, there are still many restrictions because the pandemic has not entirely receded. In some epidemicintensive areas, such as Xinjiang, online teaching will continue during a relatively long period. For teachers, this means that they need to adapt quickly to this change, including new didactic tools, strategies, materials, and methods for effective communication with students to ensure the satisfactory realization of the established pedagogical goals. It's worth to be admitted that this adaptation process is still ongoing, and our continued observation and research are needed to measure its effects.
From an objective point of view, the outbreak of the COVID-19 pandemic has indeed promoted significantly the popularization of online education. However, the concept of online education is not brand new. In fact, before the pandemic outbreak, experts and scholars worldwide have been extensively studying the modes and methods of online education (McFarlane, 2019; Selwyn, 2012). In China, compared with other disciplines, online foreign language teaching research has a long history. As early as the beginning of this century, Li Shaoru (2001), Zhao Zhongde (2002), Chen Bingbing (2004), Wang Shichen (2004) studied from different angles and languages the online foreign language teaching model based on the Internet. With the continuous development of information and communications technology, research on online foreign language teaching has become a hot spot. In Figure 1, using "online foreign language teaching" as the keywords, we have carried out a visual statics analysis of the articles published by Chinese scholars on journals includes in China National Knowledge Infrastructure (CNKI). As a result, we have observed that until 2014, the number of papers had maintained 
continuous growth, with a limited amount; since 2014, with the emergence of mobile Internet technology and personal mobile terminal equipment, relevant researches have increased significantly. According to this trend, with the further development of $5 \mathrm{G}$ technology, artificial intelligence, virtual reality technology, and the popularization of teaching concepts such as flipped classrooms, blended teaching, and experiential teaching, it's reasonable to predict a large scale of relevant researches in the future. In summary, taking the COVID-19 school closure as an experimental opportunity, it is necessary to explore how to adapt to online teaching methods, teaching tools, teaching strategies, and communication skills of online foreign language teaching.

Based on the case of the elective course of Spanish of Jinan University during the pandemic period, this article sorts out the common concepts and application models related to online learning in current days, including MOOC, SPOC, flipped classroom, and blended learning. It then introduces in detail the didactic methods and tools of the Spanish online course with its respective characteristics and advantages; finally, it analyses the challenges of online foreign language teaching and its corresponding solutions. (See "Fig. 1")

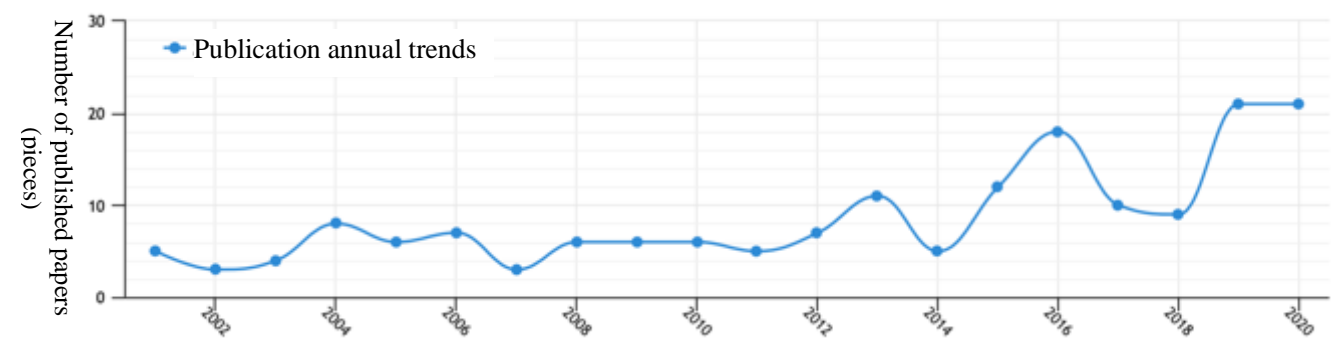

Fig. 1. Visual statics analysis of the articles published by Chinese scholars on journals includes CNKI with the keyword "online foreign language teaching".

\section{BASIC CONCEPTS AND PRACTICES OF ONLINE LEARNING}

\section{A. $M O O C$}

The interconnection of everything everywhere characterizes today's world, and the foundation of all of this is the Internet, which represents innovation, creativity, economic opportunity, and social inclusion. With the invention of Internet technology, MOOC has emerged as a substitute for face-to-face offline teaching (Hsieh, 2018). At present, MOOC has been popularized all over the world. There are currently more than 1,000 universities globally, offering more than 14,000 MOOC courses on different platforms (Ruiz-Palmero, Fernández-Lacorte, Sánchez-Rivas, \& Colomo-Magaña, 2020, p. 2). According to the connectivism theory, learning is the extension of knowledge and understanding through the network (Siemens, 2016). Compared with the traditional teaching model of closed lectures, private texts, and closed classroom discussions, the MOOC under the Internet learning environment provides an open framework, allowing teaching participants to share free resources, ideas, and experiences, communicate and innovate. GómezZermeño $(2020$, p. 586) pointed out that the challengebased learning didactic activities adopted in MOOC can effectively exercise participants' practical ability in real scenarios and make the learning effect more profound and durable; at the same time, MOOC poses a series of challenges to teachers in digital teaching design and methods.

\section{B. $S P O C$}

Generally speaking, SPOC is regarded as a supplement and derivative product of MOOC. Professor Armando Fox first proposed the concept of SPOC at the University of Berkele in 2013. Its original intention was to provide courses that are more in line with personalized learning concepts based on MOOC (Escudero-Nahón, 2020). Compared with MOOC, which provides widespread knowledge to large-scale users, SPOC can focus on smaller groups to meet their specific needs (Álvarez-Gil, Montes-Sancho, \& Tachizawa, 2017; Sarasa \& Bravo-Agapito, 2017). Generally, in universities, SPOC is used as assistant materials to the blended teaching method to help students to adjust and adapt better the pace of the course (López de la Serna, 2016; Lou, Zheng, \& Jiang, 2016; Wang, Wang, Wen, Wang, \& Tao, 2016; Zhang et al., 2019; Zheng, Chu, Wu, \& Gou, 2018). In terms of content composition, SPOC mainly focuses on short videos, supplemented by questions with automatic correction, and face to face activities. This content distribution strategy of SPOC makes it more suitable for the concept of adaptive learning in higher education than MOOC (Ruiz-Palmero et al., 2020, p. 2). 


\section{Flipped classroom and blended learning}

The flipped classroom was initially proposed in the United States in 2007. First, students watch the contents of the courses prepared by teachers or others at home; at school, students and teachers do homework and discussion sessions together. Since students' and teachers' roles are reversed, and the learning process is different from traditional teaching, it is called "flipped classroom" (Wu Qingshan, 2014). With the continuous development and maturity of information technology, based on the flipped classroom, blended learning has gradually emerged, which combines online educational materials and opportunities for interaction online with traditional place-based classroom methods. It requires both teacher and student's physical presence, with some elements of student control over time, place, path, or pace (Banditvilai, 2016; Friesen, 2014). According to some scholars' evidence-based studies, student achievement was higher in blended learning experiences compared to either fully online or fully face-to-face learning experiences (Siemens, Gašević, \& Dawson, 2015, p. 71).

\section{FORMS AND CHARACTERISTICS OF SPANISH ONLINE LEARNING DURING THE PANDEMIC}

From March 2020, all universities, primary and secondary schools in China have adopted online teaching. Although some schools in some regions resumed classroom teaching in mid-May, many schools (such as Jinan University where the author works) had continued its online teaching until the end of the semester in July. The Spanish course is an elective course for all university students, with two lecture hours per week. The course' objective is to teach basic Spanish pronunciation, grammar, vocabulary, and daily conversations to zero foundation students. In the practice of online learning, teachers have used a variety of platforms and tools, such as Rain Classroom, Tencent Conference, Chinese University Foreign Language MOOCs Platform (UMOOCs), and WeChat.

\section{A. Rain Classroom Course Management Platform}

Rain Classroom is a new intelligent teaching solution jointly launched by Tsinghua University and the Chinese company Xuetang Online. It is the latest research result of the Online Education Research Center of the Ministry of Education of China. It is committed to provide quick and freely data-based and intelligent information support for all teaching processes. Through this platform, teachers can complete announcements, course materials sharing, attendance roll call, online questioning, continuous evaluation, final exams.

- Announcement issuance: In the traditional model, teachers need to issue course notices to students through the university educational administration system. Students may miss important information; however, through the information sharing of Rain Classroom and the university educational administration system, teachers send information to students' personal WeChat to ensure that the information is comprehensive, timely, and accurately received by the students.

- Course materials sharing: In the traditional model, course materials are shared either through the school's educational administration system-such platforms are often technically lagging and limit the size and quantity of files, or through emails o WeChat groups, which are difficult to ensure that every student receives the course materials correctly; with the help of Rain Classroom, teachers can upload various course materials (including reading materials, audio and video materials, slide courseware, key and intricate knowledge of SPOC Video, homework) Once the materials have been sent, the platform will instantly send reminders to their mobile device. Meanwhile, the teacher can check the student's download and view status.

- Attendance roll call: In traditional classroom teaching, attendance roll call is often done verbally, which is inefficient; through the Rain Classroom platform, combined with IP address, GPS positioning, and face recognition, roll call can be done efficiently and accurately on mobile phones.

- Online questioning: Through Rain Classroom teachers can ask any student questions during class time and give scores to students' answers. The scores will be automatically counted by the platform and included in the course performance assessment.

- Continuous evaluation: Through Rain Classroom, teachers can continuously evaluate students' attendance, classroom interaction, homework, and final exams, and generate the final scores, which will be connected to the school's educational administration system.

- Final exam: In the traditional classroom exam, different versions of test papers, teacher invigilators, and separated seats are indispensable to avoid cheating behaviors. After the exam, the teacher will manually correct the paper and register the educational administration system results.

Through Rain Classroom, teachers only need to upload relevant questions before the exam, and the platform will automatically generate countless versions 
of the test paper. During the exam, the artificial intelligence invigilation is carried out through technologies such as camera, IP address, and face recognition. After the exam, the system corrects the test papers automatically and count the scores according to the preset standard answers, which significantly improves the entire test process's efficiency.

\section{B. Tencent conference}

Tencent Conference is an integrated video conference software developed by Tencent company of China, that was used for live teaching during the pandemic. Compared with other video conferencing software such as Skype, Zoom, and Adobe Connect, its main advantages are short time delay, multiple platforms, easy operation, and more economical fees. However, since Tencent Conference was initially designed for online conferences instead of living teaching, there are some shortcomings, mainly as follows:

- The screen recording function is not supported, so students cannot review after class (in the latest version, this function has been added).

- Unlike Rain Classroom, Tencent Meeting has not been connected to the university's educational administration system, so teachers and students must share the meeting room account password through a third-party channel to enter the online classroom.

- In classroom interaction, there is no feasible function to automatically record the process of interaction, so it is not conducive to the quantitative statistics of classroom interactions (this is the relative advantage of Adobe Connect).

The author was pleasantly surprised to find that Rain Classroom has developed a live broadcast function in the latest update, which can substitute the Tencent Conference for live teaching.

\section{Chinese university foreign language MOOCs platform(UMOOCs)}

The "Basic Spanish" of Chinese University Foreign Language MOOCs Platform UMOOCs that shares some common knowledge with our course has been fully used in our teaching process. The "Basic Spanish" comprises videos of 20-25 minutes with 3-5 multiplechoice questions that introduce the essential phonetic characteristics, basic vocabulary, and expressions of Spanish from a macro perspective. In our teaching, it is used as pre-class preparation material. MOOC, live teaching, SPOC videos, and homework formed a complete circle of flipped classrooms and blended learning.

\section{WeChat}

As the most commonly used instant messaging tool in Chinese society, WeChat has an irreplaceable status, so it is also used for teacher-student communication in online teaching. Although $\mathrm{WeChat}$ has its unique advantages as an instant messaging tool since it is not a communication tool used explicitly for teaching exchanges, we have found many shortcomings in the online teaching experience, that includes:

- Inefficient management of personnel: as communication without threshold tool, anyone can enter the group chat, when the number of people reaches a specific number, there may bring management difficulties.

- Inefficient management of information: when the number of people in the group chat has reached a certain level, the useful information will be easily covered up by many invalid and repeated information (the number of students in the studied course is nearly 90).

- Inefficient management of classroom order: it is difficult for students to link classroom behavior norms with instant messaging tools in the short term, so in some cases, the use of WeChat may make a negative impact on the classroom order.

\section{Challenges AND COUNTERMEASURES OF ONLINE FOREIGN LANGUAGE TEACHING}

\section{A. The network environment directly affects the efficiency of online teaching}

A high-quality network environment is a prerequisite to ensure the significant development of online teaching. On the one hand, the teachers' network environment directly affects the development of online teaching activities; on the other hand, students' network environment is also crucial. Jinan University's students come from all over the country, and some students live in areas where the network environment is unsatisfactory, which directly affects online teaching. In the future, with the development of 5G technology, we should have the confidence to overcome obstacles in this area.

\section{B. Lack of face-to-face classroom interaction}

Compared with other disciplines, foreign language learning focuses more on the training of students' crosscultural communication skills. Therefore, classroom interaction is essential. Whether it is flipped classroom or blended learning, face-to-face communication is indispensable. However, due to the pandemic, the teaching process must be carried out entirely online. Although most video conferencing software allows teachers and students to communicate and interact 
through video, the effect is always unsatisfactory due to the lack of context. In the future, with the continuous development of $5 \mathrm{G}$ technology, holographic technology, and virtual reality technology in education, we can explore the use of information technology to create more realistic online interaction methods.

\section{Teachers' technology capacity affects the use of didactic methods}

Whether it is pedagogical resources such as MOOC and SPOC, teaching concepts such as flipped classroom, blended learning, or various course management and live broadcast platforms, all of them have challenged traditional teaching models to vary degrees. To solve this limitation, it is necessary to strengthen the teachers' learning and understanding of modern teaching concepts, tools, and resources to keep up with the pace of information education.

\section{Lack of didactic resources suitable for online teaching}

The traditional foreign language teaching is based on the classroom environment, so its textbooks and other teaching resources are designed around classroom teaching and are not suitable for online teaching. For example, due to a lack of presence, network delays, limited class time, etc., it is not easy to conduct dialogue training in Spanish textbooks in online teaching. To solve this dilemma, it is necessary to take online teaching as the axis, consider the characteristics of online teaching, and design unique pedagogical materials and resources suitable for online teaching.

\section{CONCLUSION}

This research focuses on the Spanish courses' online teaching experience at Jinan University during the Covid-19 pandemic in the spring semester of 2020. The author has observed and reflects on the online foreign language teaching model based on MOOC and SPOC from three aspects: basic concepts and practices of online learning, the forms and characteristics of Spanish online learning during the epidemic, and the challenges countermeasures of online foreign language teaching. Through the research, it has been found that online teaching is still in its exploratory and experimental stage, with a massive space for improvement in the network environment, classroom interaction, teacher training, teaching resources, etc. Besides, to adopt a future-oriented vision, it is necessary to consider the advantages, disadvantages, opportunities, and threats that the emerging information technologies like 5G, virtual reality technology, and holographic imaging technology will bring to future online foreign language education.

Despite the promising findings of our study, limitations should be discussed as well. First, this research is mainly based on the author's own experience and observations, which lacks investigation, comparison, and summary of larger-scale samples, so there is space for improvement in representativeness; second, this research does not include a quantitative analysis of the effect. In the future, a control group experiment will be needed to investigate the difference between online teaching, face to face teaching, and blended learning in pedagogical effects ; third; our study was carried out in China. Therefore generalization of results to other countries and their educational contexts is hardly possible. However, we assume that other countries in the world face similar challenges during the COVID-19 pandemic since teachers' adapting to online teaching during complete or partial school lockdown is not a challenge that is restricted to China. All these mentioned shortcomings have left more possibilities and space for more in-depth research in the future.

\section{Acknowledgment}

This work is funded by Jinan University's XXII Education Reform Research Project (The 22nd Batch of Educational Reforms of Jinan University: Research and Practice on the Reform of Contextualized Teaching Model of Spanish as a Second Foreign Language Based on Virtual Reality Technology, Project Funding Number: 55611607.)

\section{References}

[1] Álvarez-Gil, M. J., Montes-Sancho, M. J., \& Tachizawa, E. M "A first approximation to the spocs-fc in the context of the supply chain management," WPOM-Working Papers on Operations Management, vol. 8, pp. 151-163, 2017.

[2] Banditvilai, C., "Enhancing Students' Language Skills through Blended Learning," Electronic Journal of e-Learning, vol. 14(3), pp. 220-229, 2016

[3] Chen Bingbing, "Discussion about the Authenticity of Online Language Learning," Tecnology Enhanced Foreigh Language Education, vol. 1, pp. 55-77. 2004

[4] Escudero-Nahón, A., "Análisis crítico al término "masivo" en los MOOC: una Cartografía Conceptual," Edmetic, vol. 9(1), pp 188-212, 2020

[5] Friesen, N., "Report: defining blended learning. 2012,", 2014) 2012 . DOI= http://learningspaces. org/papers/Defining_Blended_Learning_NF. pdf.

[6] Gómez-Zermeño, M. G., "Massive Open Online Courses as a Digital Learning Strategy of Education for Sustainable Development," Journal of Sustainable Development of Energy, Water and Environment Systems, vol. 8(3), pp. 577-589, 2020.

[7] Hsieh, M.Y., "Exploring the most decisive online education determinants as impacted by Taiwan's New Southbound Policy," EURASIA Journal of Mathematics, Science and Technology Education, vol. 14(5), pp. 1945-1962, 2018.

[8] Li Shaoru, "Internet and Foreigh Language Teaching," Journal of Hubei Normal University (Social Science Section), vol. 2, pp 94-97. 2001 
[9] López de la Serna, A., "Integración de los MOOC en la enseñanza universitaria,” El caso de los SPOC, 2016.

[10] Lou, I., Zheng, P., \& Jiang, C., "The Enlightenment of SPOC on Teaching Reform of Higher Education in China-Based on the Perspective of Mastery Learning Theory," Science Journal of Education, vol. 4(2), pp. 95-100, 2016.

[11] McFarlane, A. E., "Devices and desires: Competing visions of a good education in the digital age," British Journal of Educational Technology, vol. 50(3), pp. 1125-1136, 2019.

[12] Ruiz-Palmero, J., Fernández-Lacorte, J.-M., Sánchez-Rivas, E., \& Colomo-Magaña, E., "The implementation of Small Private Online Courses (SPOC) as a new approach to education," International Journal of Educational Technology in Higher Education, vol. 17(1), pp. 1-12, 2020.

[13] Sarasa, R. A., \& Bravo-Agapito, J., "Implantación de un SPOC en la educación a distancia para la mejora del proceso de enseñanza-aprendizaje," Revista Tecnología, Ciencia y Educación, vol. 4, 2017.

[14] Selwyn, N., "Education in a digital world: Global perspectives on technology and education". London: Routledge, 2012.

[15] Siemens, G., "Connectivism: a learning theory for the digital age," Elearnspace.org, 2004.

[16] Siemens, G., Gašević, D., \& Dawson, S., Preparing for the digital university: A review of the history and current state of distance, blended, and online learning, Athabasca University, 2015.

[17] Wang Shichen, "Study on Modern Russian Teaching Based on Internet," Shandong Foreign Language Teaching, vol. 4, pp. 3639, 2004

[18] Wang, X.H., Wang, J.P., Wen, F.J., Wang, J., \& Tao, J.Q., "Exploration and Practice of Blended Teaching Model Based Flipped Classroom and SPOC in Higher University," Journal of Education and Practice, vol. 7(10), pp. 99-104, 2016.

[19] Wu Qingshan, "Flipped Classroom," Journal of Education Research, vol. 238, pp. 135-136, 2014.

[20] Zhang, X.-M., Yu, J.-Y., Yang, Y., Feng, C.-P., Lyu, J., \& Xu, S.-L., "A flipped classroom method based on a small private online course in physiology," Advances in physiology education, vol. 43(3), pp. 345-349, 2019.

[21] Zhao Zhongde \& Song Jun, "E-Learning and Foreigh Language Learning," Foreigh Languages and Their Teaching, vol. 12. pp. 26-28, 2002.

[22] Zheng, M., Chu, C.-C., Wu, Y. J., \& Gou, W., "The mapping of online learning to flipped classroom: Small private online course," Sustainability, vol. 10(3), pp. 748, 2018. 